Author affiliations and support information (if applicable) appear at the end of this article.

Published at jco.org on December 27, 2016

Corresponding author: Jennifer S. Temel, MD, Division of Hematology/Oncology, Massachusetts General Hospital Cancer Center, 55 Fruit St, Yawkey 7B, Boston, MA 02114; e-mail: jtemel@partners.org

(C) 2016 by American Society of Clinical Oncology

$0732-183 X / 17 / 3508 w-834 w / \$ 20.00$

\title{
Effects of Early Integrated Palliative Care in Patients With Lung and GI Cancer: A Randomized Clinical Trial
}

Jennifer S. Temel, Joseph A. Greer, Areej El-Jawahri, William F. Pirl, Elyse R. Park, Vicki A. Jackson, Anthony L. Back, Mihir Kamdar, Juliet Jacobsen, Eva H. Chittenden, Simone P. Rinaldi, Emily R. Gallagher, Justin R. Eusebio, Zhigang Li, Alona Muzikansky, and David P. Ryan

\section{$\begin{array}{llllllll}\text { A } & \text { B } & \text { S } & \text { T } & \text { R } & \text { A } & \text { C } & \text { T }\end{array}$}

\section{Purpose}

We evaluated the impact of early integrated palliative care (PC) in patients with newly diagnosed lung and Gl cancer.

\section{Patients and Methods}

We randomly assigned patients with newly diagnosed incurable lung or noncolorectal GI cancer to receive either early integrated PC and oncology care $(n=175)$ or usual care $(n=175)$ between May 2011 and July 2015. Patients who were assigned to the intervention met with a PC clinician at least once per month until death, whereas those who received usual care consulted a PC clinician upon request. The primary end point was change in quality of life (OOL) from baseline to week 12, per scoring by the Functional Assessment of Cancer Therapy-General scale. Secondary end points included change in QOL from baseline to week 24, change in depression per the Patient Health Questionnaire-9, and differences in end-of-life communication.

\section{Results}

Intervention patients ( $v$ usual care) reported greater improvement in QOL from baseline to week 24 (1.59 $v-3.40 ; P=.010)$ but not week $12(0.39 v-1.13 ; P=.339)$. Intervention patients also reported lower depression at week 24, controlling for baseline scores (adjusted mean difference, $-1.17 ; 95 \% \mathrm{Cl},-2.33$ to $-0.01 ; P=.048$ ). Intervention effects varied by cancer type, such that intervention patients with lung cancer reported improvements in QOL and depression at 12 and 24 weeks, whereas usual care patients with lung cancer reported deterioration. Patients with $\mathrm{Gl}$ cancers in both study groups reported improvements in QOL and mood by week 12. Intervention patients versus usual care patients were more likely to discuss their wishes with their oncologist if they were dying $(30.2 \% \vee 14.5 \% ; P=.004)$.

\section{Conclusion}

For patients with newly diagnosed incurable cancers, early integrated PC improved QOL and other salient outcomes, with differential effects by cancer type. Early integrated PC may be most effective if targeted to the specific needs of each patient population.

\section{J Clin Oncol 35:834-841. (C) 2016 by American Society of Clinical Oncology}

\section{INTRODUCTION}

Growing evidence supports a new role for palliative care (PC)-trained specialists in the outpatient care of patients with advanced cancer. ${ }^{1}$ The aim of this research has been to improve symptom burden and quality of life (QOL) in these patients with high morbidity and incurable disease. ${ }^{2}$ Several randomized trials have shown that simultaneous delivery of palliative and oncology care in the outpatient setting improves patient-reported outcomes. ${ }^{3}$ For example, in patients with advanced cancer and a limited life expectancy, both telephone-based and in-person PC interventions led to improved QOL, reduced symptom burden, and greater satisfaction with care ${ }^{4-6}$; however, the impact of providing PC early in the course of disease for patients with newly diagnosed advanced cancers has received less attention. In one trial of patients with newly diagnosed metastatic nonsmall-cell lung cancer (NSCLC), early integrated PC significantly improved QOL, depression symptoms, and illness understanding. ${ }^{7,8}$ Additional studies are needed to confirm these findings in diverse cancer populations with distinct disease trajectories.

Whereas improving patient QOL and symptom burden are key goals of any supportive care intervention, the practice of PC encompasses more 
than just symptom management. ${ }^{9}$ Patients with advanced cancer often fail to understand the intent of their cancer treatment and rarely engage in discussions about their preferences for care at the end of life (EOL). ${ }^{10,11}$ Such misperceptions are associated with worse EOL-care outcomes. ${ }^{10-12}$ PC clinicians are trained to help patients understand their prognosis and treatment goals and to facilitate informed decisions about their care throughout the illness trajectory and at EOL. ${ }^{13}$ Through early integration, PC clinicians are positioned to support patients and oncologists in communicating about prognosis, treatment goals, and care preferences over time.

The goal of this study was to evaluate the effect of early integrated PC on patient-reported outcomes in a large cohort of patients with newly diagnosed, incurable cancers. We hypothesized that patients who were randomly assigned to the intervention would report better QOL, lower rates of depression, improved prognostic understanding, and more frequent discussions about their EOL-care preferences compared with those who were assigned to usual care.

\section{PATIENTS AND METHODS}

\section{Study Design}

We enrolled patients with newly diagnosed incurable cancers from Massachusetts General Hospital (MGH) in a nonblinded, randomized trial of early PC integrated with oncology care compared with usual oncology care. The Dana-Farber Cancer Institute/Harvard Cancer Center Institutional Review Board approved the study protocol, and all patients provided written informed consent.

\section{Patients}

Patients were eligible to participate if they were within 8 weeks of a diagnosis of incurable lung (NSCLC, small-cell, or mesothelioma) or noncolorectal GI (pancreatic, esophageal, gastric, or hepatobiliary) cancer. Patients were also required to receive their care at MGH, be $\geq 18$ years of age, have no history of therapy for metastatic disease, have an Eastern Cooperative Oncology Group performance status of 0 to 2, and be able to read and respond to questions in English or complete questionnaires with minimal assistance. We excluded patients who were already receiving PC services, needed immediate referral for PC or hospice, or who had significant psychiatric or other comorbid disease prohibiting participation.

Study staff screened consecutive patients who presented to the oncology clinics and notified clinicians via e-mail when patients were eligible to participate. At the time of visit, study staff placed a reminder about eligibility on patient charts. Oncology clinicians invited their patients to enroll in the study.

\section{Random Assignment}

The Office of Data Quality randomly assigned patients in a 1:1 fashion to receive early integrated PC and oncology care versus usual oncology care, stratified by cancer type, using a computer-generated number sequence, which was concealed until after group assignment.

\section{Procedures}

Patients who were assigned to early PC met with a member of the outpatient PC team within 4 weeks of enrollment and at least once per month until death. Consisting of physicians and advanced practice nurses, the MGH outpatient team practices per guidelines of the National Consensus Project for Quality Palliative Care. ${ }^{14}$ PC clinicians contacted patients via telephone when an in-person visit was not possible. The patient, oncologist, or PC clinician could schedule additional PC visits at their discretion. Finally, for patients who were admitted to MGH, the inpatient PC team observed them throughout their hospitalization.
Patients who were assigned to usual oncology care were able to meet with a PC clinician only upon request by the oncologist, patient, or family. When these patients received PC services, they did not cross study groups or follow the intervention protocol. All patients, regardless of group assignment, continued to receive routine oncology care throughout the study period.

\section{Patient-Reported Outcome Measures}

We measured QOL with the 27-item Functional Assessment of Cancer Therapy-General (FACT-G) scale, which assesses four dimensions of QOL (physical, functional, emotional, and social well-being). ${ }^{15}$ To evaluate mood and anxiety, patients completed the Patient Health Questionnaire-9 (PHQ-9) and the Hospital Anxiety and Depression Scale (HADS). ${ }^{16,17}$ The PHQ-9 is a nine-item measure that detects symptoms of major depressive disorder according to the criteria of the Diagnostic and Statistical Manual of Mental Disorders-IV, with higher scores indicating worse depression. ${ }^{17}$ The 14 -item HADS consists of two subscales that assess anxiety and depression symptoms. Subscale scores range from 0 (no distress) to 21 (maximum distress).

We used the Prognosis and Treatment Perceptions Questionnaire developed by El-Jawahri et al ${ }^{18}$ to measure patients' understanding of their prognosis and report of their communication with oncologists. The 13 items inquire about patient information preferences, perceptions of their prognosis and health status, and communication about their prognosis and EOL preferences.

\section{Data Collection}

Patients completed a demographic questionnaire and baseline selfreport measures after providing written informed consent and before random assignment. Follow-up assessments occurred at 12 weeks and 24 weeks(or within 3 weeks of those time points). Protocol staff who were separate from the research team administered study questionnaires. Patients who were unable to complete questionnaires in clinic received the questionnaires by e-mail or mail. In addition, PC clinicians used a studyspecific, Web-based data capture tool to access a standardized template and record the focus of their clinic visits after each outpatient encounter and once during any hospitalization.

\section{Statistical Analysis}

We performed statistical analyses using STATA software (version 9.3; STATA, College Station, TX; Computing Resource Center, Santa Monica, CA) and R software (version 3.3.1; The R Foundation, Vienna, Austria). Data obtained through May 2016 were included. The primary outcome was change in FACT-G score from baseline to 12 weeks; a 4- to 5-point change in FACT-G score is considered clinically meaningful. We estimated that with 280 patients, the study would have $80 \%$ power to detect a 4 -point difference in the change in FACT-G scores from baseline to 12 weeks between study groups (with $P<.05$ ). Given the rate of missing data observed in our previous study, we increased our sample size to 350 patients.

To examine QOL and mood we used independent-samples $t$ tests and analysis of covariance (ANCOVA) models that controlled for baseline criterion scores and potential confounders such as age and comorbidity, which were imbalanced between groups and associated with outcomes of interest. We also used ANCOVA to explore whether the effect of intervention on outcomes varied by cancer cohort, that is, cancer cohort $\times$ group assignment interaction. Observing an interaction effect $(P<.15),{ }^{19}$ we then conducted separate subgroup analyses in the lung and GI cancer cohorts with ANCOVA to assess the effect of intervention on QOL and mood.

We also compared patient-reported outcomes between the two groups by using a terminal decline joint modeling approach, which models the trend in outcomes backward from death, rather than prospectively from enrollment ${ }^{20}$. We did not prespecify the use of this approach in our protocol as it was first published in 2013, after initiation of this study; however, this technique offers an advantageous approach to account for deterioration in patient-reported outcomes closer to death and uses a mixed-effects model for longitudinal outcomes to provide valid estimates 
for missing data. ${ }^{20}$ We estimated terminal decline and survival distributions with semiparametric models, comparing QOL and mood between study groups at 2, 4, and 6 months before death. All models adjusted for baseline criterion scores and potential confounders such as age and comorbidity. Given the observed interaction effect between cancer type and intervention effect, we also conducted subgroup analyses in the lung and GI cancer cohorts using terminal decline.

\section{RESULTS}

\section{Baseline Characteristics}

Three hundred fifty patients enrolled in the study (Appendix Fig A1, online only) between May 2, 2011 and July 20, 2015. Patients were mostly white $(92.3 \%)$, with a mean age of 64.84 years (standard deviation, 10.88 years), and $54.0 \%$ were male. Intervention patients were slightly older and had greater comorbidities than did those in the usual care group (Table 1).

\section{PC Visits}

The mean number of PC visits by 24 weeks was 6.54 (range, 0 to 14 ) in the intervention group and 0.89 visits (range, 0 to 7 ) in the usual care group. The PC team met with $20.0 \%$ and $34.3 \%$ of usual care patients by weeks 12 and 24, respectively. Figure 1 depicts the number of PC visits by study group and the content PC clinicians addressed with intervention patients by 24 weeks.

\section{QOL and Mood}

Intervention patients reported a mean 0.39-point increase in FACT-G scores from baseline to 12 weeks compared with usual care patients who reported a 1.13-point decrease from baseline $(\mathrm{t}[296]=-0.96 ; \mathrm{SE}=1.59 ; P=.339$; Cohen's d, 0.11). At 24 weeks, intervention patients reported a 1.59-point increase in FACT-G scores from baseline whereas usual care patients reported a 3.40-point decrease from baseline $(\mathrm{t}[238]=-2.59$; $\mathrm{SE}=1.93$; $P=.010$; Cohen's d, 0.33). Patient PHQ-9, HADS-Depression, and HADS-Anxiety scores did not differ significantly between study groups from baseline to weeks 12 or 24; however, ANCOVA models that controlled for baseline variables demonstrated significant differences that favored the intervention for FACT-G and PHQ-9 scores at 24 weeks (Table 2). Using the terminal decline model, intervention participants had significantly higher QOL (FACT-G) and lower depression symptom (PHQ-9) scores at 2 and 4 months, but not at 6 months, before death (Table 3). Use of psychosocial services, including psychiatry, psychology, and social work, did not differ between study groups (data not shown).

\section{Prognostic Understanding and Communication}

At 12 weeks, similar proportions of patients in both study groups reported that their primary goal of cancer treatment was cure (intervention, $28.7 \%$ [ $\mathrm{n}=41$ of 143] $v$ usual care, $34.5 \%$ [ $\mathrm{n}=50$ of 145]; $P=.289$ ). However, intervention patients were more likely than usual care patients to report that knowing about their prognosis was "very helpful" or "extremely helpful" in making decisions about treatment $(96.5 \%$ [ $=110$ of 114$] \vee 89.8 \%$ [ $=115$ of 128$]$; $P=.043)$ and coping with the disease $(97.3 \%[\mathrm{n}=108$ of 111$) v 83.6 \%$ $[\mathrm{n}=107$ of 128$] ; P<.001)$ at 12 weeks. At 24 weeks, more

\begin{tabular}{|c|c|c|}
\hline Characteristic & $\begin{array}{c}\text { Usual Care }(n=175) \\
\text { No. }(\%)\end{array}$ & $\begin{array}{c}\text { Early PC }(n=175) \\
\text { No. }(\%)\end{array}$ \\
\hline Mean age, years (SD) & $64.03(10.46)$ & $65.64(11.26)$ \\
\hline Male & $98(56.0)$ & $91(52.0)$ \\
\hline \multicolumn{3}{|l|}{ Ethnicity } \\
\hline White & $167(95.4)$ & $156(89.1)$ \\
\hline American Indian & $0(0.0)$ & $4(2.3)$ \\
\hline Asian & $3(1.7)$ & $5(2.9)$ \\
\hline Black & $4(2.3)$ & $6(3.4)$ \\
\hline Hispanic or Latino & $2(1.1)$ & $7(4.0)$ \\
\hline Other & $1(0.6)$ & $4(2.3)$ \\
\hline \multicolumn{3}{|l|}{ Religion } \\
\hline Catholic & $103(59.2)$ & $98(56.0)$ \\
\hline Protestant & $36(20.7)$ & $26(14.9)$ \\
\hline Jewish & $2(1.1)$ & $14(8.0)$ \\
\hline Muslim & $2(1.1)$ & $1(0.6)$ \\
\hline None & $21(12.1)$ & 20 (11.4) \\
\hline Other & $10(5.7)$ & $16(9.1)$ \\
\hline \multicolumn{3}{|l|}{ Relationship status } \\
\hline Married or partnership & $124(70.9)$ & $121(69.1)$ \\
\hline Single & $17(9.7)$ & $17(9.7)$ \\
\hline Divorced or separated & $18(10.3)$ & $18(10.3)$ \\
\hline Widowed & $16(9.1)$ & 19 (10.9) \\
\hline \multicolumn{3}{|l|}{ Education } \\
\hline High school or less & $73(41.7)$ & $58(33.1)$ \\
\hline Some or completed college & 69 (39.4) & 76 (43.4) \\
\hline Graduate school & 33 (18.9) & $41(23.4)$ \\
\hline \multicolumn{3}{|l|}{ Cancer type } \\
\hline Lung & 96 (54.9) & $95(54.3)$ \\
\hline Non-small-cell & 74 & 80 \\
\hline Small-cell & 17 & 13 \\
\hline Neuroendocrine & 3 & 1 \\
\hline Mesothelioma & 2 & 1 \\
\hline EGFR mutation & 10 & 19 \\
\hline ALK translocation & 4 & 4 \\
\hline GI & $79(45.1)$ & $80(45.7)$ \\
\hline Pancreatic & 43 & 44 \\
\hline Esophageal/GE junction & 17 & 15 \\
\hline Gastric & 4 & 3 \\
\hline Hepatobiliary & 15 & 18 \\
\hline \multicolumn{3}{|l|}{ Smoking status } \\
\hline $\begin{array}{l}\text { Never smoker } \\
\quad \text { or }<10 \text { pack-years }\end{array}$ & 67 (38.3) & 75 (42.9) \\
\hline Current or former smoker & $95(54.3)$ & $93(53.1)$ \\
\hline Unknown & $13(7.4)$ & $7(4.0)$ \\
\hline \multicolumn{3}{|l|}{ ECOG PS } \\
\hline 0 & $43(24.6)$ & $45(25.7)$ \\
\hline 1 & $115(65.7)$ & $116(66.3)$ \\
\hline 2 & $17(9.7)$ & $14(8.0)$ \\
\hline $\begin{array}{l}\text { Charlson Comorbidity Index } \\
\text { score, mean (SD) }\end{array}$ & $6.73(1.39)$ & $7.03(1.35)$ \\
\hline FACT-G score, mean (SD) & 77.79 (15.46) & $78.84(14.90)$ \\
\hline PHQ-9 score, mean (SD) & $6.50(5.19)$ & $6.39(5.49)$ \\
\hline $\begin{array}{l}\text { HADS-Depression subscale } \\
\text { score, mean (SD) }\end{array}$ & $4.58(3.73)$ & $4.72(4.28)$ \\
\hline $\begin{array}{l}\text { HADS-Anxiety subscale score, } \\
\text { mean (SD) }\end{array}$ & $5.57(3.88)$ & 5.05 (3.95) \\
\hline \multicolumn{3}{|c|}{$\begin{array}{l}\text { Abbreviations: ALK, anaplastic lymphoma kinase; ECOG PS, Eastern Co- } \\
\text { operative Oncology Group performance status; EGFR, epidermal growth factor } \\
\text { receptor; FACT-G, Functional Assessment of Cancer Therapy-General scale; GE, } \\
\text { gastroesophageal; HADS, Hospital Anxiety and Depression Scale; PC, palliative } \\
\text { care; PHQ-9, Patient Health Questionnaire-9; SD, standard deviation. }\end{array}$} \\
\hline
\end{tabular}

intervention patients reported that they had discussed their EOL wishes with their oncologist compared with usual care patients (30.2\% [ $\mathrm{n}=35$ of 116$] v 14.5 \%$ [ $\mathrm{n}=17$ of 117$] ; P=.004)$. Study groups did not differ with respect to information preferences, 


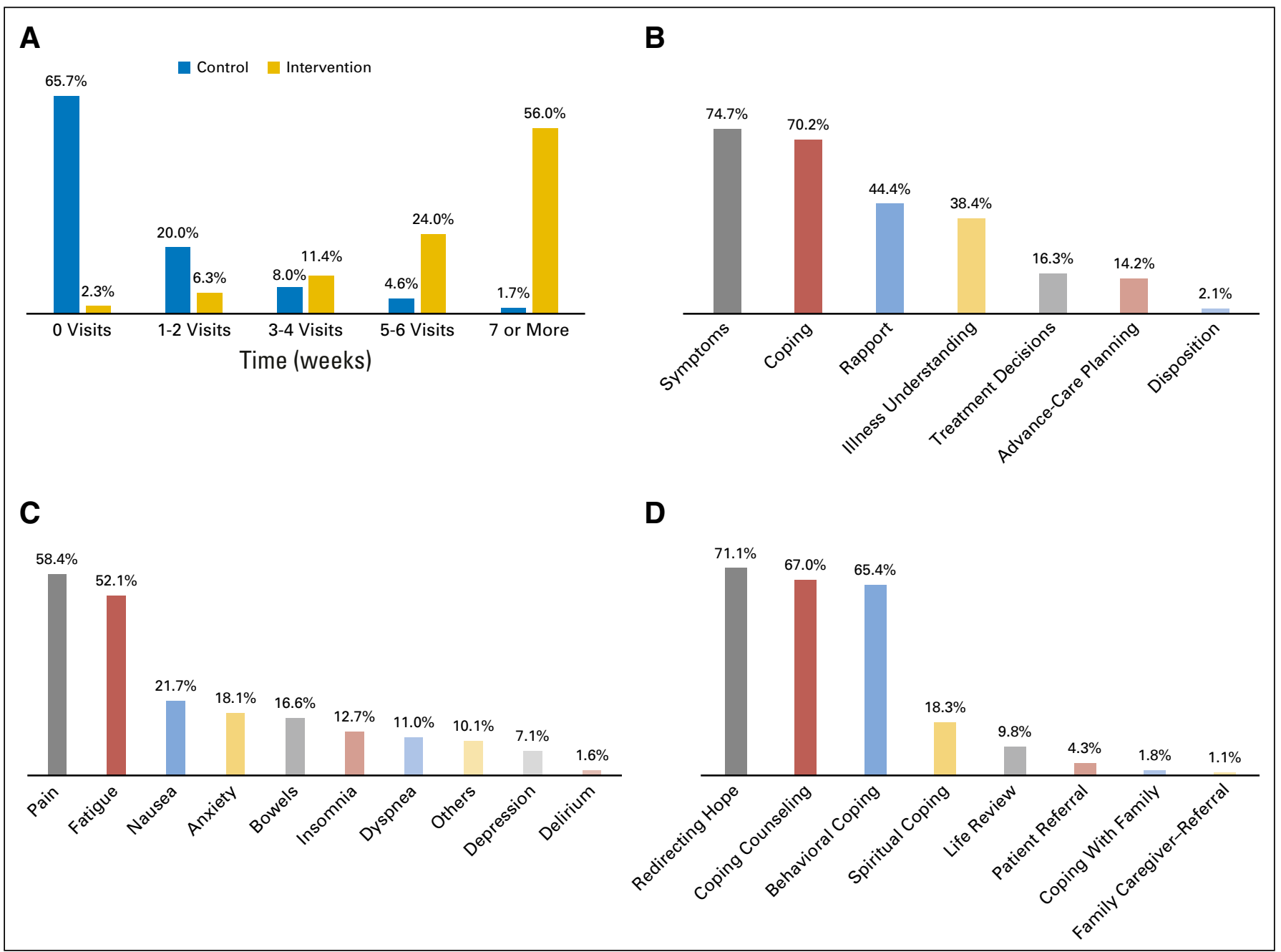

Fig 1. Frequency and content of palliative care $(P C)$ visits. (A) Number of PC visits by study group. Bars represent the percentage of PC visits for all study patients within 24 weeks. Four intervention patients withdrew from the study before their first scheduled PC visit. (B) Content areas of PC visits with intervention patients per PC clinician documentation. PC clinicians used a standardized template to electronically document the focus of their intervention visits after each encounter. Bars represent the proportion of PC visits that focused on each content area within 24 weeks. (C) Bars represent the proportion of visits that each symptom was addressed when PC noted symptoms as a visit focus. (D) Bars represent the proportion of visits that each topic was addressed when PC noted coping as a visit focus.

frequency of conversations about prognosis, or rating of the quality of information.

\section{Effect of PC Intervention by Cancer Type}

Figure 2 depicts QOL and depression data longitudinally by cancer cohort. Effects of the intervention varied by cancer cohort over time for both FACT-G (cancer cohort $\times$ group assignment interaction $\mathrm{F}[1,291]=2.94 ; P=.088$ ) and PHQ-9 (cancer cohort $\times$ group assignment interaction $\mathrm{F}[1,293]=3.05 ; P=.082$ ) scores. We therefore conducted separate subgroup analyses to examine differences in outcomes for the lung and GI cancer cohorts. ANCOVA models that controlled for baseline variables demonstrated significant intervention effects in the lung cancer cohort for FACT-G and PHQ-9 scores at both 12 and 24 weeks, but not in the GI cohort (Table 2).

By using the terminal decline model, intervention participants with lung cancer had significantly higher QOL and lower depression symptom scores at 2, 4, and 6 months before death. In contrast, QOL and depression did not differ between study groups in the GI cancer cohort before death (Table 3). Given these results, we explored characteristics between patients with lung and GI cancer and found no differences in baseline measures or in the number of PC visits among those patients who received intervention (Appendix Table A1, online only). However, the GI cancer cohort had a higher proportion of male patients and a greater number of hospitalizations from baseline to week 24 compared with the lung cancer cohort.

\section{DISCUSSION}

The results from this trial add to the growing literature on the benefits of integrating PC services earlier in the course of disease for patients with advanced cancer. We not only confirmed previous findings that early integrated PC improves QOL and mood in patients with incurable cancers, but also that these positive effects on 


\begin{tabular}{|c|c|c|c|c|c|c|}
\hline Cohort & No. & $\begin{array}{l}\text { Usual Care, Adjusted } \\
\text { Mean }(95 \% \mathrm{Cl})\end{array}$ & $\begin{array}{c}\text { Early Care, Adjusted } \\
\text { Mean }(95 \% \mathrm{Cl})\end{array}$ & $\begin{array}{l}\text { Adjusted Mean } \\
\text { Difference (SE) }\end{array}$ & $95 \% \mathrm{Cl}$ & $P$ \\
\hline \multicolumn{7}{|c|}{ Entire sample } \\
\hline \multicolumn{7}{|c|}{ 12-week outcomes } \\
\hline FACT-G score & 298 & 77.70 (75.77 to 79.63 ) & 80.10 (78.11 to 82.08 ) & $2.40(1.41)$ & $(-0.38$ to 5.18$)$ & .091 \\
\hline PHQ-9 score & 300 & 6.33 (5.65 to 7.01$)$ & 5.55 (4.85 to 6.25$)$ & $-0.78(0.50)$ & $(-1.76$ to 0.21$)$ & .121 \\
\hline \multicolumn{7}{|c|}{ 24-week outcomes } \\
\hline FACT-G score & 240 & 75.90 (73.59 to 78.21$)$ & 81.26 (78.89 to 83.63 ) & 5.36 (1.69) & (2.04 to 8.69 ) & .002 \\
\hline PHQ-9 score & 239 & 6.72 (5.91 to 7.53$)$ & 5.55 (4.72 to 6.37$)$ & $-1.17(0.59)$ & $(-2.33$ to -0.01$)$ & .048 \\
\hline \multicolumn{7}{|l|}{ Lung cancer } \\
\hline \multicolumn{7}{|c|}{ 12-week outcomes } \\
\hline FACT-G score & 159 & 74.37 (71.38 to 77.36 ) & 79.41 (76.32 to 82.51$)$ & $5.04(2.21)$ & (0.68 to 9.41$)$ & .024 \\
\hline PHQ-9 score & 161 & 7.21 (6.18 to 8.24$)$ & 5.61 (4.55 to 6.66 ) & $-1.61(0.76)$ & $(-3.10$ to -0.11$)$ & .035 \\
\hline \multicolumn{7}{|c|}{ 24-week outcomes } \\
\hline FACT-G score & 130 & 75.62 (72.18 to 79.07$)$ & 82.15 (78.81 to 85.48$)$ & $6.52(2.48)$ & (1.62 to 11.42$)$ & .010 \\
\hline PHQ-9 score & 130 & 6.71 (5.90 to 7.53 ) & 5.54 (4.72 to 6.37$)$ & $-1.17(0.59)$ & $(-2.33$ to -0.01$)$ & .048 \\
\hline \multicolumn{7}{|c|}{ GI cancer } \\
\hline \multicolumn{7}{|c|}{ 12-week outcomes } \\
\hline FACT-G score & 139 & 81.32 (79.01 to 83.63 ) & 81.09 (78.74 to 83.45$)$ & $-0.23(1.67)$ & ( -3.53 to 3.08$)$ & .892 \\
\hline PHQ-9 score & 139 & 5.34 (4.45 to 6.23$)$ & 5.44 (4.53 to 6.35$)$ & $0.11(0.64)$ & $(-1.17$ to 1.38$)$ & .870 \\
\hline \multicolumn{7}{|c|}{ 24-week outcomes } \\
\hline FACT-G score & 110 & 75.96 (72.76 to 79.15$)$ & 80.35 (76.85 to 83.85 ) & 4.39 (2.39) & ( -0.36 to 9.14$)$ & .070 \\
\hline PHQ-9 score & 109 & 6.57 (5.41 to 7.74$)$ & 6.19 (4.92 to 7.46$)$ & $-0.38(0.87)$ & $(-2.11$ to 1.34$)$ & .659 \\
\hline
\end{tabular}

patient outcomes vary by cancer type. We further identified new benefits of the integrated PC model in improving patients' ability to cope with their prognosis and in enhancing their communication about EOL-care preferences with clinicians. Of importance, these data elucidate key elements of the early PC intervention, encompassing much more than symptom management.
Given our prior study in patients with advanced NSCLC, ${ }^{21}$ the primary outcome of this trial was change in QOL from baseline to 12 weeks; however, we did not detect a significant improvement in QOL with early integrated PC until the 24-week time point. These results are consistent with the three prior randomized trials of early PC that all failed to show a significant improvement in QOL at

\begin{tabular}{|c|c|c|c|c|c|c|}
\hline \multirow[b]{2}{*}{ Cohort } & \multicolumn{2}{|c|}{2 Months Before Death } & \multicolumn{2}{|c|}{4 Months Before Death } & \multicolumn{2}{|c|}{6 Months Before Death } \\
\hline & Mean $(95 \% \mathrm{Cl})$ & $P$ & Mean $(95 \% \mathrm{Cl})$ & $P$ & Mean $(95 \% \mathrm{Cl})$ & $P$ \\
\hline \multicolumn{7}{|l|}{ Entire sample } \\
\hline FACT-G score & & .016 & & .011 & & .430 \\
\hline Early PC & 75.67 (73.14 to 78.20$)$ & & 82.06 (79.96 to 84.17$)$ & & 81.44 (78.96 to 83.91$)$ & \\
\hline Usual care & 71.44 (69.14 to 73.76$)$ & & 78.22 (76.14 to 80.30$)$ & & 79.99 (77.35 to 82.62$)$ & \\
\hline PHQ-9 score & & .046 & & .042 & & .991 \\
\hline Early PC & 7.04 (6.15 to 7.93$)$ & & 6.17 (5.43 to 6.84$)$ & & 5.36 (4.51 to 6.21$)$ & \\
\hline Usual care & $8.29(7.45$ to 9.13$)$ & & $6.86(6.69$ to 7.75$)$ & & 5.37 (4.28 to 6.45$)$ & \\
\hline \multicolumn{7}{|l|}{ Lung cancer } \\
\hline FACT-G score & & .022 & & .010 & & .013 \\
\hline Early PC & 75.74 (72.21 to 79.27$)$ & & 82.22 (78.99 to 85.44$)$ & & 82.53 (79.52 to 85.53$)$ & \\
\hline Usual care & $70.03(66.65$ to 73.41$)$ & & 76.24 (73.04 to 79.45$)$ & & 77.12 (74.14 to 80.45$)$ & \\
\hline PHQ-9 score & & .009 & & .004 & & .011 \\
\hline Early PC & 6.12 (4.91 to 7.32$)$ & & 5.69 (4.73 to 6.65$)$ & & 5.27 (4.30 to 6.23$)$ & \\
\hline Usual care & 8.35 (7.18 to 9.52$)$ & & 7.70 (6.76 to 8.64$)$ & & 7.05 (6.10 to 8.00$)$ & \\
\hline \multicolumn{7}{|l|}{ GI cancer } \\
\hline FACT-G score & & .231 & & .258 & & .998 \\
\hline Early PC & 76.23 (72.73 to 79.74$)$ & & 81.97 (79.23 to 84.72$)$ & & 81.87 (79.30 to 84.44$)$ & \\
\hline Usual care & 73.52 (70.77 to 76.26$)$ & & 79.79 (77.18 to 82.41$)$ & & 81.88 (79.34 to 84.42$)$ & \\
\hline PHQ-9 score & & .631 & & .594 & & .842 \\
\hline Early PC & 7.85 (6.53 to 9.17$)$ & & 5.94 (4.90 to 6.98$)$ & & 5.28 (4.30 to 6.27$)$ & \\
\hline Usual care & 7.44 (6.38 to 8.49$)$ & & 5.55 (4.56 to 6.54$)$ & & 5.14 (4.18 to 6.11$)$ & \\
\hline
\end{tabular}




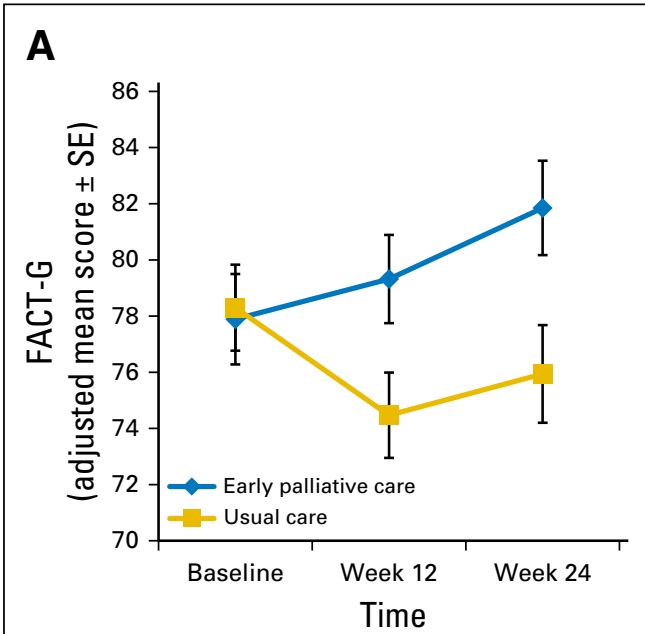

C

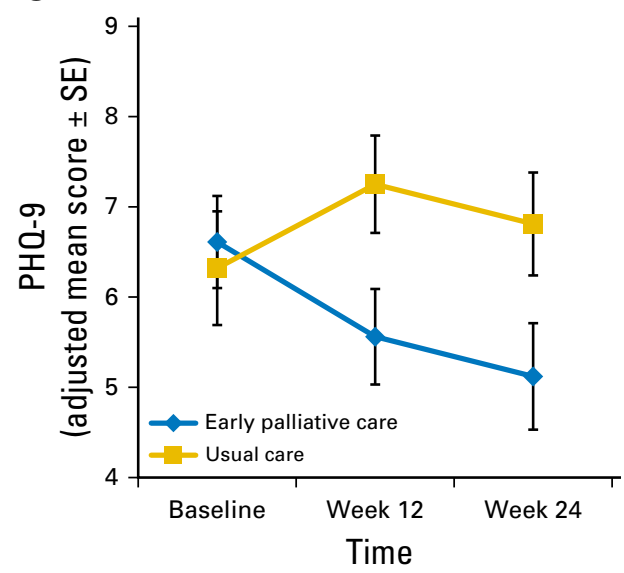

B

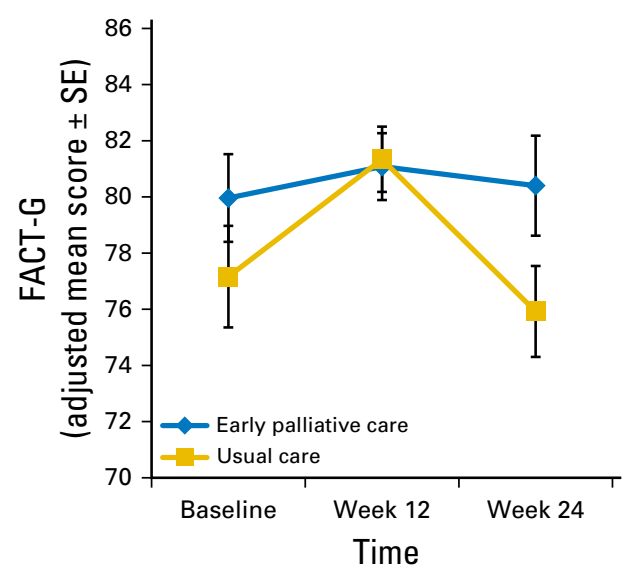

D

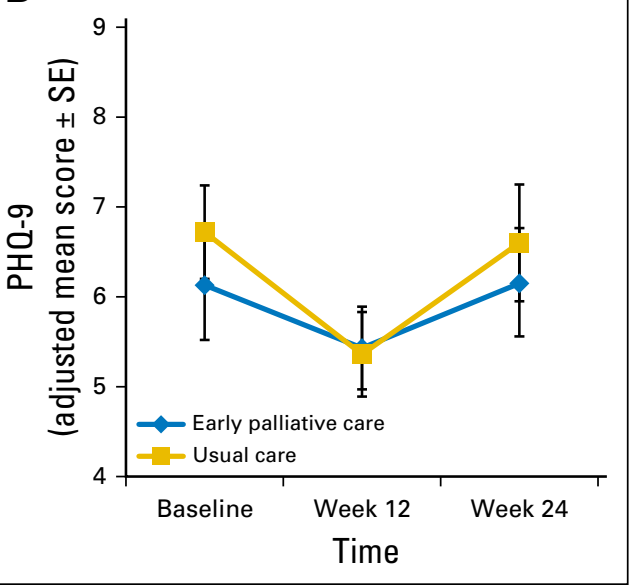

Fig 2. Trajectories of quality of life (OOL) and depression symptoms over time by cancer cohort. (A) $\mathrm{QOL}$ in lung cancer. (B) $\mathrm{QOL}$ in $\mathrm{Gl}$ cancer. (C) Depression symptoms in lung cancer. (D) Depression symptoms in GI cancer. FACT-G, Functional Assessment of Cancer Therapy-General scale; PHO-9, Patient Health Questionnaire-9.
12 weeks. ${ }^{4,5,22}$ Similar to the Educate, Nurture, Advise, Before Life Ends (ENABLE) Project, our terminal decline analysis confirmed that patients assigned to early integrated PC reported better QOL and mood in the months before death. ${ }^{4}$ Thus, longer follow-up might be needed to fully assess the effect of the early PC model on patient-reported outcomes.

Prior randomized trials of PC interventions included patients with different cancer diagnoses with considerable heterogeneity in their time from diagnosis, clinical course, and overall survival. Given these trials in mixed cancer populations, we did not expect differential outcomes by cancer type. Whereas subgroup analyses are exploratory, we did demonstrate differences in study outcomes between patients with lung and GI cancers. Similar to our previous study, patients with lung cancer who received usual care reported worsened QOL from baseline to 12 weeks, whereas intervention patients had improved QOL over this timeframe. ${ }^{7}$ This QOL difference in the lung cancer cohort became even more pronounced by 24 weeks and in the months before death. In contrast, regardless of group assignment, the GI cohort reported an improvement in their QOL over the initial 12 weeks of the trial, with no differences in study outcomes in the months before death. Thus, the QOL and mood trajectories, as well as the impact of PC integration on these patient-reported outcomes, vary between patients with lung and GI cancers. Although further research is needed to understand these differences, a possible explanation for these findings is that patients with GI cancer spent significantly more time in the hospital than did patients with lung cancer, which may have affected their QOL and mood. In future work, investigators should explore the role of targeted PC interventions to address the specialized needs of specific cancer populations with particular attention to appropriate timing for PC integration within the context of patients' illness trajectories.

This trial is the first, to our knowledge, to show an effect of early PC on patients' communication about EOL-care preferences. We observed that intervention patients were twice as likely to report that they had discussed their EOL-care wishes compared with usual care patients. Intervention patients were also more likely to report that knowing about their prognoses helped them make decisions about treatment and to cope with their illness. As a clinical care model, PC intervention in this trial was not strictly manualized. ${ }^{5,7}$ In contrast, a recent study of a structured communication intervention delivered by PC clinicians in the intensive care unit failed to improve family caregiver-reported outcomes. ${ }^{23}$ Allowing PC clinicians the freedom to address the concerns that are most salient for the patient may be the optimal approach to provide personalized care; however, this patient-centered approach has also made it challenging to describe the elements of early PC intervention. Results from this trial regarding both the nature of the 
PC visits and the impact of early PC on patients' coping and communication shed new light on the key processes of this care model. Whereas symptom management is a core component of PC, providing patients with the skills they need to cope with and communicate about their life-threatening illness is another essential element of PC for patients with advanced cancer.

Our study has several limitations. First, patients and clinicians were not blinded to group assignment. Second, we did not anticipate the difference in QOL and mood trajectories between patients with lung and GI cancers; thus, we did not plan the sample size to evaluate outcomes by cancer subtype. Third, because usual care at our institution often entails involvement of PC in the outpatient setting, more than one third of patients who were assigned to usual care met with the PC team during the first 24 weeks of the study. This contact may have diluted the effect of the intervention, though such practice likely represents current national standards. Similarly, our PC team has been well integrated in our cancer center for the last decade, which has perhaps enhanced the PC skills of oncologists. ${ }^{24}$ Lastly, we conducted the trial at a single institution with a predominantly white and English-speaking population, which may limit the generalizability of the results to other care settings and clinical populations.

Early integration of palliative and oncology care in patients with newly diagnosed incurable cancers improves QOL, reduces depression symptoms, and enhances coping with prognosis and communication about EOL-care preferences. These findings provide further evidence to support early integrated PC as the standard of care for patients with newly diagnosed incurable cancers. With the recent Dying in America $^{25}$ report strongly urging research to improve patient-clinician communication about EOL care, the finding that intervention patients were twice as likely as usual care patients to discuss EOL-care preferences is notable and timely. Although the outcomes of this trial demonstrate meaningful benefits of early PC, they raise new questions about how best to integrate and evaluate PC in populations with different disease and QOL trajectories. This study also highlights the complexities of studying supportive care interventions during a time of rapid advances in cancer treatment, as recent discoveries are having an undeniable impact on patient survival, but also perhaps on QOL and mood. Thus, further research is needed to define optimal PC delivery models that target the specific needs of different patient populations in the modern era of cancer therapeutics.

\section{AUTHORS' DISCLOSURES OF POTENTIAL CONFLICTS OF INTEREST}

Disclosures provided by the authors are available with this article at jco.org.

\section{AUTHOR CONTRIBUTIONS}

Conception and design: Jennifer S. Temel, Joseph A. Greer, Areej El-Jawahri, William F. Pirl, Elyse R. Park, Vicki A. Jackson, Anthony L. Back, Mihir Kamdar, Juliet Jacobsen, Eva H. Chittenden, Simone P. Rinaldi, David P. Ryan

Collection and assembly of data: Jennifer S. Temel, Joseph A. Greer, Areej El-Jawahri, Vicki A. Jackson, Emily R. Gallagher, Justin R. Eusebio

Data analysis and interpretation: Jennifer S. Temel, Joseph A. Greer, Areej El-Jawahri, Zhigang Li, Alona Muzikansky

Manuscript writing: All authors

Final approval of manuscript: All authors

Accountable for all aspects of the work: All authors

\section{REFERENCES}

1. Hui $D$, Bruera $E$ : Integrating palliative care into the trajectory of cancer care. Nat Rev Clin Oncol 13: 159-171, 2016

2. Zimmermann $C$, Riechelmann $R$, Krzyzanowska $M$, et al: Effectiveness of specialized palliative care: $A$ systematic review. JAMA 299:1698-1709, 2008

3. Smith TJ, Temin S, Alesi ER, et al: American Society of Clinical Oncology provisional clinical opinion: The integration of palliative care into standard oncology care. J Clin Oncol 30:880-887, 2012

4. Bakitas M, Lyons KD, Hegel MT, et al: Effects of a palliative care intervention on clinical outcomes in patients with advanced cancer: The Project ENABLE II randomized controlled trial. JAMA 302:741-749, 2009

5. Zimmermann C, Swami N, Krzyzanowska M, et al: Early palliative care for patients with advanced cancer: A cluster-randomised controlled trial. Lancet 383:1721-1730, 2014

6. Ferrell $B$, Sun $V$, Hurria $A$, et al: Interdisciplinary palliative care for patients with lung cancer. J Pain Symptom Manage 50:758-767, 2015

7. Temel JS, Greer JA, Muzikansky A, et al: Early palliative care for patients with metastatic non-smallcell lung cancer. N Engl J Med 363:733-742, 2010

8. Temel JS, Greer JA, Admane $S$, et al: Longitudinal perceptions of prognosis and goals of therapy in patients with metastatic non-small-cell lung cancer: Results of a randomized study of early palliative care. J Clin Oncol 29:2319-2326, 2011
9. Ferrell $B$, Connor SR, Cordes $A$, et al: The national agenda for quality palliative care: The $\mathrm{Na}$ tional Consensus Project and the National Quality Forum. J Pain Symptom Manage 33:737-744, 2007

10. Weeks JC, Catalano PJ, Cronin A, et al: Patients' expectations about effects of chemotherapy for advanced cancer. N Engl J Med 367:1616-1625, 2012

11. Wright $A A$, Zhang $B$, Ray $A$, et al: Associations between end-of-life discussions, patient mental health, medical care near death, and caregiver bereavement adjustment. JAMA 300:1665-1673, 2008

12. Zhang $B$, Wright $A A$, Huskamp $H A$, et al: Health care costs in the last week of life: associations with end-of-life conversations. Arch Intern Med 169: 480-488, 2009

13. Jackson VA, Jacobsen J, Greer JA, et al: The cultivation of prognostic awareness through the provision of early palliative care in the ambulatory setting: A communication guide. J Palliat Med 16:894-900, 2013

14. National Consensus Project for Quality Palliative Care: The clinical practice guidelines for quality palliative care (ed 3). http://www.nationalconsensusproject.org/ NCP_Clinical_Practice_Guidelines_3rd_Edition.pdf.

15. Cella D, Hahn EA, Dineen K: Meaningful change in cancer-specific quality of life scores: Differences between improvement and worsening. Qual Life Res 11:207-221, 2002

16. Zigmond AS, Snaith RP: The hospital anxiety and depression scale. Acta Psychiatr Scand 67: 361-370, 1983

17. Kroenke $K$, Spitzer $R L$, Williams JB: The PHQ-9: Validity of a brief depression severity measure. J Gen Intern Med 16:606-613, 2001
18. El-Jawahri $A$, Traeger $L$, Park ER, et al: Associations among prognostic understanding, quality of life, and mood in patients with advanced cancer. Cancer 120:278-285, 2014

19. Wang $\mathrm{R}$, Ware JH: Detecting moderator effects using subgroup analyses. Prev Sci 14:111-120, 2013

20. Li Z, Tosteson TD, Bakitas MA: Joint modeling quality of life and survival using a terminal decline model in palliative care studies. Stat Med 32: 1394-1406, 2013

21. Back $A L$, Park ER, Greer JA, et al: Clinician roles in early integrated palliative care for patients with advanced cancer: A qualitative study. J Palliat Med 17:1244-1248, 2014

22. Bakitas MA, Tosteson TD, Li Z, et al: Early versus delayed initiation of concurrent palliative oncology care: Patient outcomes in the ENABLE III randomized controlled trial. J Clin Oncol 33: 1438-1445, 2015

23. Carson SS, Cox CE, Wallenstein S, et al: Effect of palliative care-led meetings for families of patients with chronic critical illness: A randomized clinical trial. JAMA 316:51-62, 2016

24. Temel JS, Jackson VA, Billings JA, et al: Phase II study: Integrated palliative care in newly diagnosed advanced non-small-cell lung cancer patients. J Clin Oncol 25:2377-2382, 2007

25. Dying in America: Improving Quality and Honoring Individual Preferences Near the End of Life. Washington, DC, National Academies Press, 2015 


\section{Affiliations}

Jennifer S. Temel, Joseph A. Greer, Areej El-Jawahri, William F. Pirl, Elyse R. Park, Vicki A. Jackson, Mihir Kamdar, Juliet Jacobsen, Eva H. Chittenden, Simone P. Rinaldi, Emily R. Gallagher, Justin R. Eusebio, Alona Muzikansky, and David P. Ryan, Massachusetts General Hospital; Jennifer S. Temel, Joseph A. Greer, Areej El-Jawahri, William F. Pirl, Elyse R. Park, Vicki A. Jackson, Mihir Kamdar, Juliet Jacobsen, Eva H. Chittenden, Alona Muzikansky, and David P. Ryan, Harvard Medical School, Boston, MA; Anthony L. Back, University of Washington, Seattle, WA; and Zhigang Li, Geisel School of Medicine at Dartmouth, Lebanon, NH.

\section{Support}

Supported by the National Institutes of Health Grant No. NCT01401907 and National Institute of Nursing Research Grant No. R01NR012735.

\section{JCO_Exceptionally Quick Review Process}

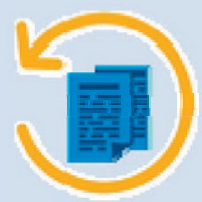

JCO offers a Rapid Review and Rapid Communications program that publishes novel, timely research online within 4-6 weeks of the original submission date. This is made possible by a dynamic panel of editors with far-ranging specialties, supported by an immense database of respected scientific reviewers and biostatisticians.

Submit to JCO: please visit http://submit.jco.org 


\section{AUTHORS' DISCLOSURES OF POTENTIAL CONFLICTS OF INTEREST}

Effects of Early Integrated Palliative Care in Patients with Lung and GI Cancer: A Randomized Clinical Trial

The following represents disclosure information provided by authors of this manuscript. All relationships are considered compensated. Relationships are self-held unless noted. I = Immediate Family Member, Inst = My Institution. Relationships may not relate to the subject matter of this manuscript. For more information about ASCO's conflict of interest policy, please refer to www.asco.org/rwc or ascopubs.org/jco/site/ifc.

Jennifer S. Temel

Research Funding: Helsinn Therapeutics (Inst), Pfizer (Inst)

Joseph A. Greer

No relationship to disclose

Areej El-Jawahri

No relationship to disclose

William F. Pirl

No relationship to disclose

Elyse R. Park

Other Relationship: UpToDate royalties

Vicki A. Jackson

No relationship to disclose

Anthony L. Back

No relationship to disclose

Mihir Kamdar

Stock or Other Ownership: Amorsa Therapeutics Consulting or Advisory Role: Amorsa Therapeutics Expert Testimony: Thomas and Wan LLP

Juliet Jacobsen

No relationship to disclose
Eva H. Chittenden

No relationship to disclose

Simone P. Rinaldi

No relationship to disclose

Emily R. Gallagher

No relationship to disclose

Justin R. Eusebio

No relationship to disclose

Zhigang Li

No relationship to disclose

Alona Muzikansky

No relationship to disclose

David P. Ryan

Stock or Other Ownership: MPM Capital

Honoraria: UpToDate, Research to Practice

Consulting or Advisory Role: MPM Capital

Patents, Royalties, Other Intellectual Property: McGraw Hill Chapter royalties, Johns Hopkins University Press 


\section{Acknowledgment}

We thank the patients and their families who participated in this study and the clinicians from the palliative care, GI, and thoracic clinics at the Massachusetts General Hospital Cancer Center.

\section{Appendix}

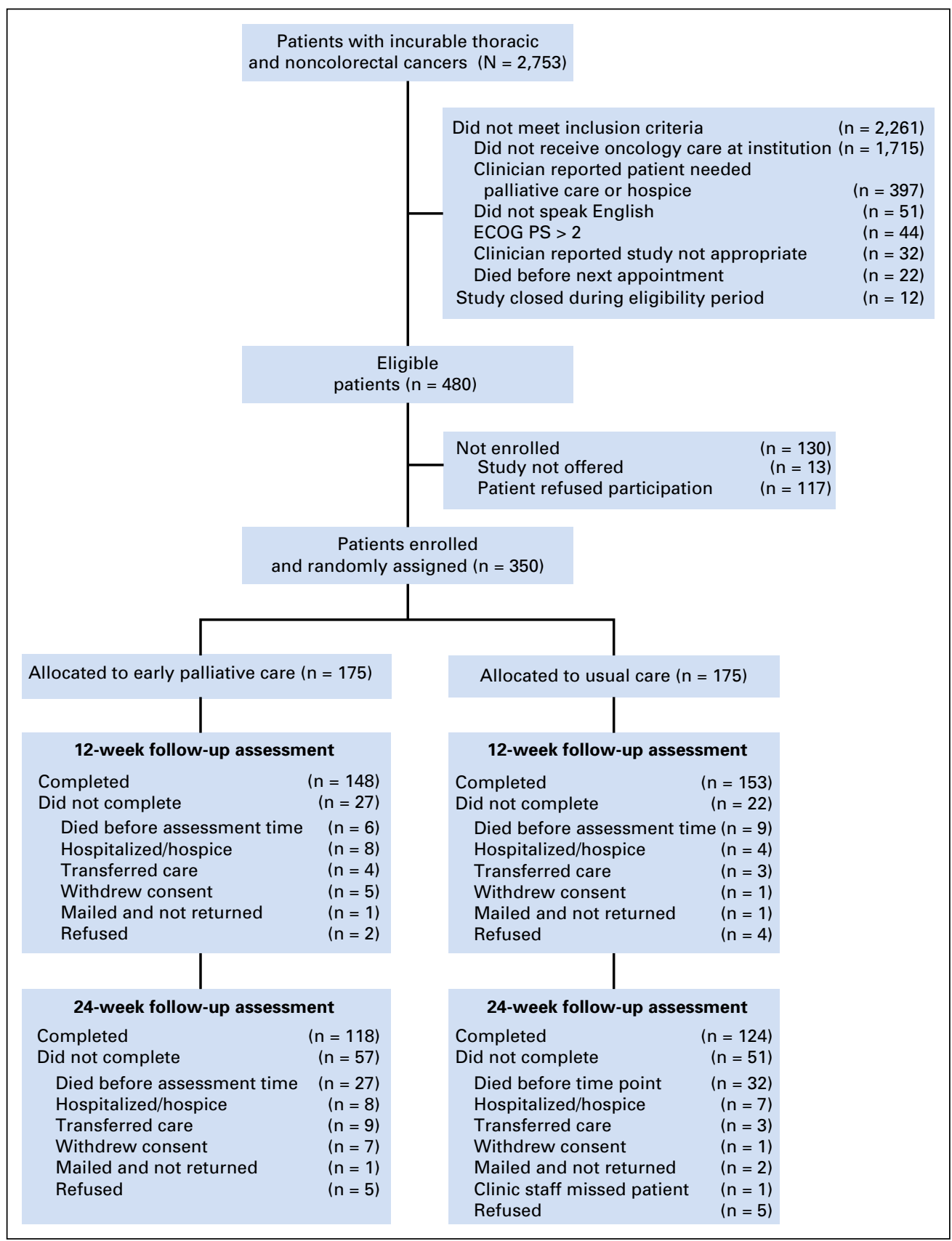

Fig. A1. CONSORT diagram. ECOG PS, Eastern Cooperative Oncology Group performance status. 
Temel et al

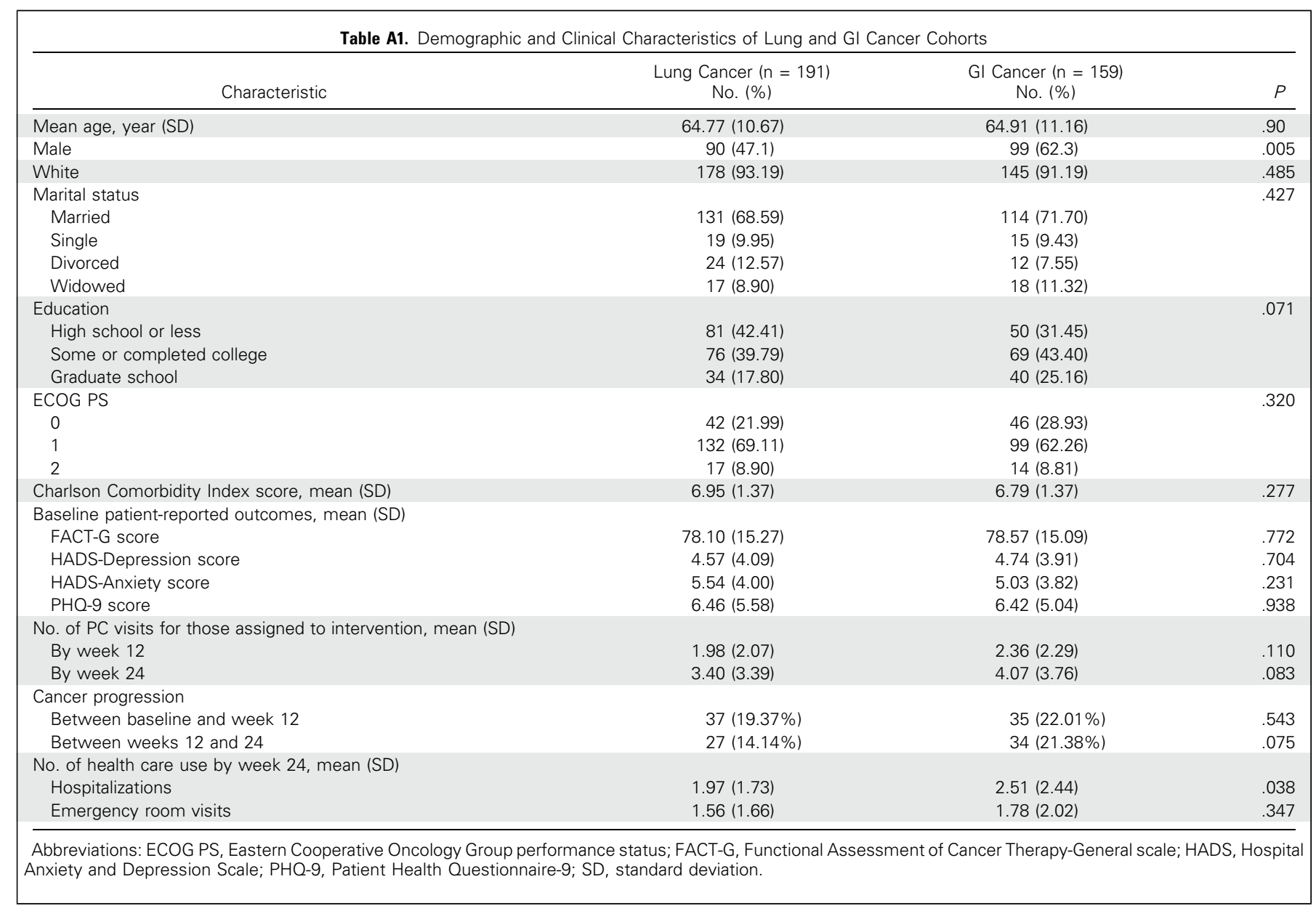

